\section{The psycho gene}

\author{
While the idea of a 'criminal gene' is nonsense, there is growing evidence \\ that some psychopathic behaviour might indeed be grounded in genes
}

\section{Philip Hunter}

T he notion that genes play an important role in many diseases has been widely accepted, but many find it much harder to acknowledge a similar link with particular behaviour or even predisposition to crime. Partly for this reason, the study of behavioural genetics remains a controversial topic, with disagreement not just over the science itself, but even more so about the therapeutic, societal and legal implications.

Too much might have been made too soon of early findings that made correlations between alleles of certain genes and tendencies to antisocial or criminal behaviour. Indeed, most researchers in the field were appalled by the decision of an Italian appeal court in 2009 to cut the sentence of a convicted murderer by one year on the grounds that he had a version of the MAOA gene, which has been linked to aggression and violence (Feresin, 2009). There is equal dismay over some US courts that went the other way and accepted genetic factors as evidence for the prosecution, leading to higher sentences on the basis that people with particular alleles cannot be cured and will remain a risk to society for longer.

"Taking genetic factors into account when sentencing is plain stupid, unless we are talking about something like Down's syndrome or some other syndrome that drastically reduces intelligence and executive functioning," insisted Anthony Walsh from the Criminal Justice Department at Boise State University in Idaho, USA. "This is the kind of "genetic determinism" that liberals have worried themselves silly over. They just have to take one or two neuroscience and genetic classes to dispense with their 'my genes/neurons' made me do it. Nothing relieves one of the obligation to behave civilized."

$\mathrm{N}$ onetheless, the case against specific alleles has been accumulating, notably for the low-expression variant of $M A O A$, known as MAOA-L, which has been linked in various studies with increased risk of violent and aggressive behaviour. The gene MAOA encodes monoamine oxidase $\mathrm{A}$, an enzyme that degrades amine neurotransmitters, such as dopamine, noradrenalin and serotonin. A rare genetic disorder caused by an MAOA mutation leads to MAOA deficiency and in turn an excess of monoamine transmitters, causing excessive impulsive behaviour including hypersexuality, sleep disorder and extreme mood swings as well as a tendency to violence, which is known as Brunner syndrome.

\section{... the study of behavioural genetics remains a controversial topic, with disagreement not just over the science itself, but even more so about the therapeutic, societal and legal implications}

But while Brunner's syndrome is rare, having only been identified in five males of one extended family, the MAOA- $L$ variant is extremely common and occurs in about $40 \%$ of the population. Clearly, most of these people are peaceable and have never committed a crime, and yet a study involving researchers from Austria, Italy and the USA - headed by Andreas MeyerLindenberg, Director of the Central Institute of Mental Health in Mannheim, Germanyhas discovered that at least males with this variant had neurobiological structural factors that would predispose them to violence (Meyer et al, 2006).

Using structural MRI scanning, the study identified that people with MAOA- $L$ were more likely to have a smaller limbic system-the hippocampus, amygdala, anterior thalamic nuclei and limbic cortex-which participates in emotion, behaviour and long-term memory. The team then applied functional MRI, which measures changes in blood flow, and discovered that the MAOA-L group also showed hyperresponsiveness of the amygdala during tasks such as copying facial expressions. The amygdala is associated with emotional processing and the MAOA- $L$ group was less able to inhibit strong emotional impulses.

But some trigger is still needed to tip $M A O A-L$ people towards violence. An earlier study suggested that this trigger could be persistent maltreatment during childhood (Caspi et al, 2002). At first sight, this suggests that nearly half the human population are predisposed to violence given these triggers, but the situation is not quite that bad-it is merely nearly half of men. Women are protected in two ways: the MAOA gene is linked to the $\mathrm{X}$ chromosome so that women with the MAOA-L variety on one chromosome usually have a normal allele on the other; and there is circumstantial evidence that women are also protected by other genes from being disposed to violence.

In any case, caution is needed to interpret the findings of Mayer-Lindenberg's group about the MAOA- $L$ allele, according to Ahmad Hariri, Investigator at the Institute for Genome Sciences \& Policy at Duke University (Durham, NC, USA). "This is a significant basic science finding linking genes to brain to behaviour," he said. "But it is not a significant clinical finding in and of itself. Only in as much as this very, very, very subtle bias in the brain tips the balance toward an aggressive response to provocation is this finding even remotely clinically relevant." In fact, as Meyer-Lindenberg himself has commented, the MAOA- $L$ allele is just one of several genes-most of which are still not identified-that increase risk of violent or antisocial behaviour.

B ut the whole story takes a rather different turn in the case of psychopathy, which is now widely regarded as a congenital state characterized by lack of empathy or moral compass and defined at least partly by genes, in contrast to other forms of sociopathy or antisocial personality disorder (APD), in which environmental factors make a major contribution (Fontaine \& Viding, 2008).

"Psychopathy does seem to be heritable, and appears to have its basis at least in part in "biological" factors linked to basic emotional systems, so that the mature psychopath never develops a complete set of

“Taking genetic factors into account when sentencing is plain stupid..." 
$\cdot$

A science és society

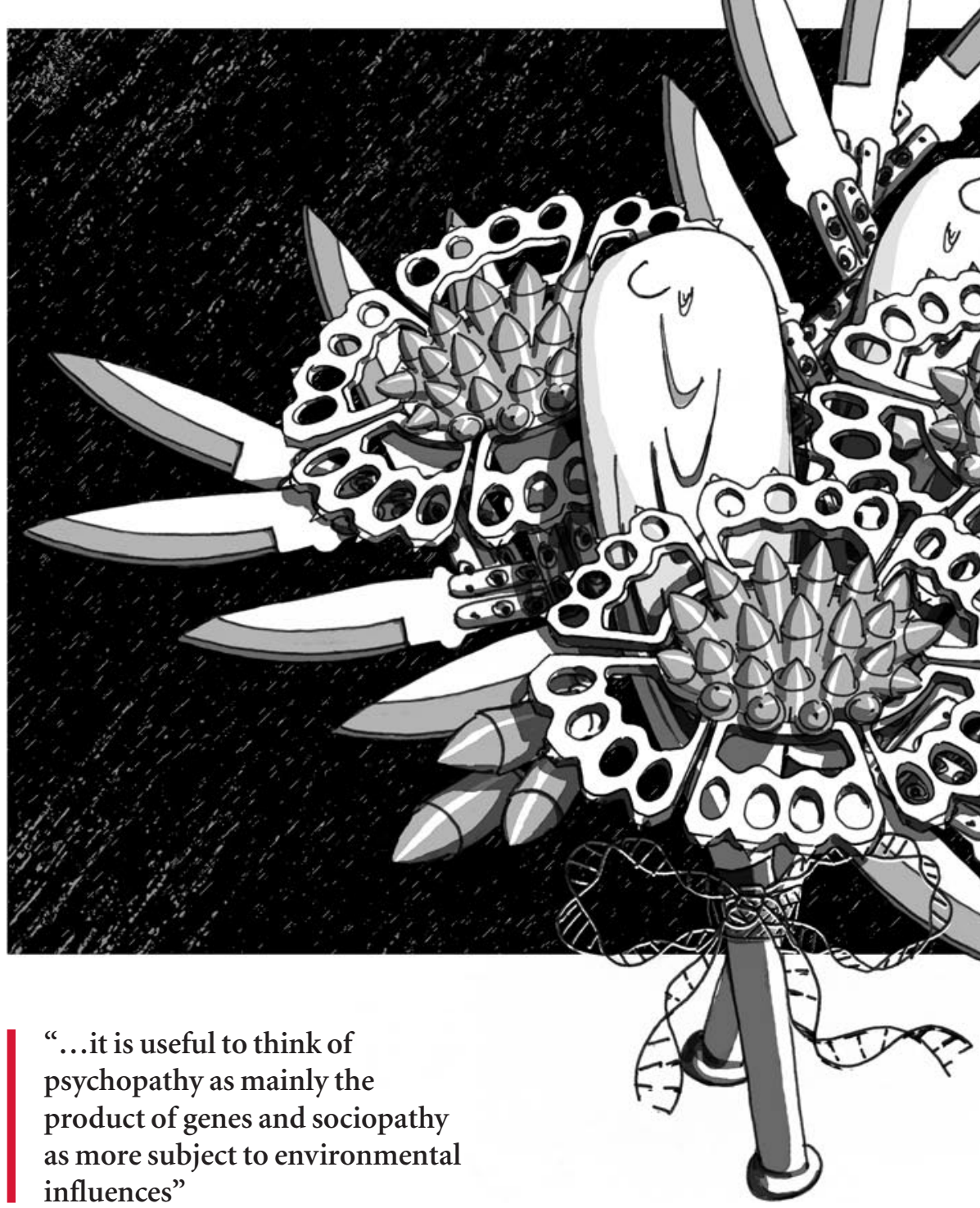

pro-social emotions like empathy, guilt, and the ability to truly care about and for others," said Richard Wiebe, who specializes in the link between psychology and criminology at Fitchburg State College in Fitchburg, MA, USA. Wiebe added though that the heritability of underlying genetic factors had yet to be conclusively established. "In other words, we know that the dependent variable, that is psychopathy, is heritable, but not enough about its causes to say that they are heritable. Nevertheless it is useful to think of psychopathy as mainly the product of genes and sociopathy as more subject to environmental influences."

Environmental factors do play a part in the behaviour of psychopaths, but in a different way than in other people who develop antisocial tendencies. The condition is more common than was once thought and affects about $0.6 \%$ of the population, according to a recent study conducted in the UK (Coid et al, 2009). Obviously, psychopathy does not always lead to crime or extreme violent behaviour; indeed its occurrence in the population used to be significantly underestimated because it was diagnosed only in people who had already shown extreme behaviour when many psychopaths do not.

As there is no genetic or clinical test as yet, psychopathy is still diagnosed in terms of behaviour, but taking account of various factors in combination. Robert Hare, who led the UK study and is now at the Department of Psychology of the University of British Columbia in Vancouver, Canada, has designed a test known as the 'Psychopathy Checklist-Revised' of about 20 symptoms that he uses to diagnose psychopathy. These include pathological lying, superficial charm, lack of empathy and guilt, proneness to boredom and sexual promiscuity.

Although it is not part of the Hare checklist, psychopaths can also be detected by their lack of a "startle reflex", which means failure of their nervous system to respond to images or events that frighten or shock other people, such as pictures of a decapitated corpse. These tests work just as well for psychopaths who have never indulged in violence and apparently lead normal lives. They can also be used to identify psychopathy in children, who exhibit the same symptoms, in particular pathological lying, lack of empathy, tendency to violence, and lack of startle reflex-in fact, several studies have found evidence of inherited psychopathy in quite young children (Viding et al, 2005).

\footnotetext{
$\mathrm{t}$ also appears that psychopathy is more common in men than women. This supports the theory that psychopathy might be an adaptive personality trait that gives men a reproductive advantage through greater tendency and ability to form numerous relationships and so have more children. This is unproven, but it is certainly true
} 
that male psychopaths tend to form large numbers of short-term relationships and can have an almost seductive charm.

However, the trait would lose its advantage if it became too common in the population. A particular trait tends only to be advantageous in certain environmental conditions as was pointed out in the context of psychopathy by Essi Viding, Co-Director of the Developmental Risk and Resilience Unit at the Department of Psychology at University College London, UK. "I think that the simple game of evolution is to ensure survival of the species under different environmental conditions," she said. "In some conditions it may be adaptive to be anxious and cooperative, in other conditions it may be good to exploit and be antisocial. This of course is effectively contrasting alleles that have very different effects. Hence, the same allele may serve an individual very well (and in a socially acceptable manner) in one situation, but not in another."

\section{...psychopathy might be an adaptive personality trait that gives men a reproductive advantage through greater tendency and ability to form numerous relationships and so have more children}

This leads back to the observation that psychopathy seems to be more common in men than women, which could have two possible explanations. First, it might be true at the genetic and neurological level, in particular if some of the relevant genes are linked to the $X$ chromosome. Yet, this is speculative as few genes have been identified that contribute specifically to psychopathy, with most of the evidence for its heritability being statistical. There is the case of the X-linked MAOA gene, but that has only been associated with general antisocial tendencies.

There is in any case an alternative explanation for the apparent gender difference in psychopathic prevalence. Alice Jones, specialist in childhood and adolescent

\section{... irrespective of where future research leads, genes should not influence sentencing decisions one way or the other because they can never be deemed responsible for behaviour}

psychopathy and antisocial behaviour at Goldsmiths College, University of London, UK, suggests that the condition could be much more common among women than studies suggest . It might be that women will, in many cases, fail to register on the Hare Psychopathy Checklist-Revised because the more extreme traits are cushioned by other female factors. "There is some evidence to support this idea," said Jones, citing work by Randy Salekin at the University of Alabama, in the USA (Salekin et al, 1997) who found that just as many women as men pass the Hare test in terms of their lack of empathy, but not on the more violent and impulsive criteria. "So, while the interpersonal aspects of psychopathy seem to be present and similar in males and females, the behavioural aspects of psychopathy are very much male-heavy," said Jones.

$\mathrm{T}$ his comes back to the question of treatment and sentencing. Viding argues that irrespective of where future research leads, genes should not influence sentencing decisions one way or the other because they can never be deemed responsible for behaviour. "Any gene alone will be neither necessary, nor sufficient to predispose someone to high levels of psychopathic traits and as such, the responsibility for choosing to offend still resides with an individual," she said. "Most 'risk genes' are common in the population and yet do not cause the majority of the individuals carrying them to offend."

But the situation is different when it comes to treatment-the appropriate therapy will depend on underlying personality tendencies. Psychopaths tend not to respond well to punishment because they cannot associate it with acts they do not consider in any way morally wrong, according to Jones. But they are more likely to respond to reward. "One example of this is currently underway at a school in Buckinghamshire (UK) for primary aged children with Emotional and Behavioural Difficulties," said Jones. "There have been very encouraging reports from teachers so far. The intervention is largely reward based, and the pupils gain rewards by working toward reaching their behavioural targets each week. Pupils can 'cashin' their rewards daily, or they can save them up for a more substantial reward later in the week."

Whether this will help these children to lead constructive adult lives remains to be seen. It does provide further evidence though that while it might not be possible to cure psychopaths, it may be possible to direct their selfish tendencies away from crime and violence towards more positive and creative activities.

\section{REFERENCES}

Caspi A, McClay J, Moffitt TE, Mill J, Martin J, Craig IW, Taylor A, Poulton R (2002) Role of genotype in the cycle of violence in maltreated children. Science 297: 851-854

Coid J, Yang M, Ullrich S, Roberts A, Hare RD

(2009) Prevalence and correlates of psychopathic traits in the household population of Great Britain. Int / Law Psychiatry 32: 65-73

Feresin E (2009) Lighter sentence for murderer with 'bad genes'. Nature doi:10.1038/news.2009.1050 Fontaine N, Viding E (2008) Genetics of personality disorder. Psychiatry 7: 137-141

Meyer JH, Ginovart N, Boovariwala A, Sagrati S, Hussey D, Garcia A, Young T, PraschakRieder N, Wilson AA, Houle S (2006) Elevated monoamine oxidase $A$ levels in the brain: an explanation for the monoamine imbalance of major depression. Arch Gen Psychiatry 63: 1209-1216

Salekin RT, Rogers R, Sewell W (1997) Construct validity of psychopathy in female offender sample: a multitrait-multimethod evaluation. J Abnorm Psychol 106: 576-585

Viding E, Blair RJR, Moffitt TE, Plomin R (2005) Evidence for substantial genetic risk for psychopathy in 7-year-olds. J Child Psychol Psychiatry 46: 592-597

\section{Philip Hunter is a freelance journalist} in London, UK.

EMBO reports (2010) 11, 667-669. doi:10.1038/embor.2010.122 